\title{
Job Satisfaction and Related Factors in Physicians and Nurses Who Work in Hospitals in Edirne City of Turkey
}

\author{
Fatmanur Ince Ozgenel ${ }^{1,}$, , Safak Meric Ozgenel $^{2}$, Galip Ekuklu ${ }^{1}$ \\ ${ }^{1}$ Department of Public Health, Trakya University Medical Faculty, Edirne, Turkey \\ ${ }^{2}$ Department of Internal Medicine, Osmangazi University, Eskisehir, Turkey
}

Email address:

fatmanur_ince@hotmail.com(F. I. Ozgenel),mozgenel@ogu.edu.tr(S.M. Ozgenel), ekuklu@hotmail.com(G. Ekuklu)

${ }^{*}$ Corresponding author

\section{To cite this article:}

Fatmanur Ince Ozgenel, Safak Meric Ozgenel, Galip Ekuklu. Job Satisfaction and Related Factors in Physicians and Nurses Who Work in Hospitals in Edirne City of Turkey. World Journal of Public Health. Vol. 3, No. 2, 2018, pp. $42-47$.

doi: 10.11648/j.wjph.20180302.12

Received: April 15, 2018; Accepted: May 5, 2018; Published: May 29, 2018

\begin{abstract}
One of the most important conditions for individuals to be happy and productive in workplaces is job satisfaction. In this study, it was aimed to determine the levels of job satisfaction in physicans and nurses who worked in hospitals in Edirne and to evaluate the effects of potential influencing factors on job satisfaction. The population of the study was composed of a total of 1376 individuals. The sample group was composed of a total of 385 healthcare staffs including 192 physicians and 193 nurses (28\% of the population). The data were collected using a questionnaire form and Minnesota Job Satisfaction Scale and evaluated by SPSS (Statistical Package for Social Sciences) 20.0 package program. Job satisfaction levels were found better in the healthcare staffs who worked in private hospital. When assessed by profession, the highest level of job satisfaction was found in academic member. This study was found that $82 \%$ of the health staffs reported that they did not feel safe while working, 75\% were exposed to verbal or physical abuse. When the satisfaction of the participants related to the institution where they worked and the occupation they had was examined, it was observed that approximately $37 \%$ reported that they thought to leave the institution where they worked and $25 \%$ even reported that they thought quitting their jobs. The general job satisfaction was better in individuals who were experts in their areas, who worked in private hospital, who loved their profession, whose working hours were regular, who felt themselves safe in their institutions and who worked free from violence. The worst level of job satisfaction was found in general practitioners. The job satisfaction of healthcare staffs who thought that the performance-based payment system applied in Turkey was unfair was low.
\end{abstract}

Keywords: Job Satisfaction, Healthcare Staff, Minnesota Job Satisfaction Scale

\section{Introduction}

Job satisfaction, an indispensable part of people's daily life to be happy and more productive, is a very important issue among physicians and nurses who focus on human health. The concept of job satisfaction which is defined as a reaction of the employees' feelings related with their jobs is dependent on individual and institutional factors. Physical and psychological health of the individuals with a high level of job satisfaction are affected positively and their life satisfaction is increased. In the institutional point of view, stress and adaptation problems experienced by the individuals with a low level of job satisfaction decrease the productivity in the job environment $[1,2]$.
When evaluating the job satisfaction of employees, intrinsic, extrinsic and general job satisfaction scores are assessed. Intrinsic satisfaction reflects the characteristics of the employee including success, being recognized, being appreciated, job responsibility and change of position related with advancement or promotion at work. Extrinsic satisfaction reflects the aspects including institutional politics and administration, type of supervision, the manner of the administrator, relations with workmates and juniors, working conditions and salary. The state where these components are evaluated together is expressed with general job satisfaction score [3].

The aim of this study was to determine the levels of job satisfaction in physicians and nurses who worked in hospitals in Edirne Central District and to evaluate potential related 
factors on job satisfaction.

\section{Methods}

The population of the study was composed of a total of 1376 individuals including 686 physicians and 690 nurses who were working in Trakya University Hospital (TUH) in Edirne central district, Edirne State Hospital and a private hospital. The sample group of the study was composed of a total of 385 healthcare staffs including 192 physicians and 193 nurses (28\% of the population). Multistage stratified sampling method was used in this study. The population was stratified by institutions, occupations, suboccupation categories (academicians, general practitioner etc.) and gender and the participants were determined with simple random sampling according to the weight of each stratum in the population.

In this study, a data collection form which was created by the investigators based on literature screening and the Minnesota Satisfaction Questionnaire (MSQ) composed of 20 questions for which the Turkish validity and reliability study was performed in 1985 by Baycan were used [4]. The data collection form included 52 questions which questioned the demographic properties, data related with working environment and potential independent variables which were thought to affect job satisfaction. Pre-application of this form was performed in 10 individuals composed of physicians and nurses who were working in TUH and would not be included in the sample. The final version of the form was created in accordance with the recommendations.

After the stage of data collection, the information obtained was entered on the computer and the analyses were performed using Statistical Package for Social Sciences (SPSS) 20.0 package program. t-test and its variations were used for analysis of continuous variables. Chi-square test was used for analysis of discrete variables. A $p$ value of $<0.05$ was considered significant in all statistical analyses.

Ethical approval was obtained from the Trakya University Ethical Review Committee. The work conforms to the provisions of the Declaration of Helsinki and the written consents of the subjects have been acknowledged.

\section{Results}

The general job satisfaction was better in individuals who were experts in their areas, who worked in private hospitals, whose job definitions were specified, who loved their profession, whose working hours were regular, who felt themselves safe in their institutions and who worked free from violence. The worst level of job satisfaction was found in general practitioners.

Sixty percent of 385 healthcare staffs were female. Approximately $75 \%$ were aged between 20 and 40 years. $34.5 \%$ had a bachelor's degree and $2 / 3$ were married.
Half of the sample of the study was composed of physicians and the other half was composed of nurses. When the total working time in the job was examined, condensation was observed in 5-10 years $(28.0 \%)$. The answers given to the question of total working time constantly in the institution were mostly intensified in the option of "less than 5 years" $(57.9 \%) . \% 41$ of the healthcare staffs included in the study were working in internal medicine.

When the satisfaction of the participants related to the institution where they worked and the occupation they had was examined, it was observed that approximately $37 \%$ reported that they thought to leave the institution where they worked and $25 \%$ even reported that they thought quitting their jobs.

Table 1 shows the distribution of the daily working hours of the participants by occupational groups and institutions. Accordingly, the working time was related with occupations and titles in both hospitals excluding the private hospital. Research assistants and nurses in TUH and general practitioners and nurses in the state hospital were working overtime with a higher rate $(\mathrm{p}<0.05)$.

Table 1. Distribution of daily working hours by institutions and occupational groups.

\begin{tabular}{llll}
\hline \multirow{2}{*}{ Institution } & Daily working hours & & \\
\cline { 2 - 4 } & Title & Mean \pm SD & p \\
\hline \multirow{2}{*}{ Trakya University } & Academicians & $7.1 \pm 3.4$ & \\
Hospital & Research assistants & $9.6 \pm 4.3$ & 0.001 \\
& Nurses & $6.7 \pm 4.1$ & \\
\multirow{2}{*}{ State hospital } & Nurses & $9.1 \pm 3.1$ & \\
& Specialist physicians & $7.5 \pm 2.7$ & 0.001 \\
\multirow{2}{*}{ Private hospital } & General practitioners & $13.6 \pm 7.8$ & \\
& Nurses & $9.1 \pm 2.6$ & \multirow{2}{*}{0.053} \\
\hline
\end{tabular}

$75 \%$ of the healthcare staffs reported that they had been exposed to verbal or physical abuse by patients and their relatives. The very interesting matter was that one of ten healthcare staffs experienced this abuse continuously. When the healthcare staffs were asked if they experienced psychological trauma, two of every three healthcare staffs answered "Yes, I do experience psychological trauma".

$82 \%$ of the healthcare staffs thought that they had no life safety or their life safety was not assured in the institutions where they worked. Widespread violence experienced in these institutions with heavy work load where people with health problems refer actually supports the accuracy of considerations related to safety.

When examining the title of job satisfaction which was one of the main objectives of the study, intrinsic, extrinsic and general job satisfaction scores were used. The intrinsic, extrinsic and general satisfaction scores of the healthcare staffs who worked in the private hospital were higher compared to the ones who worked in TUH and the State hospital. Each three mean scores were similar in the healthcare staffs who worked in TUH and the State hospital. (Table 2). 
Table 2. Distribution of the Minnesota Satisfaction scale scores of the healthcare staffs included in the study by institutions.

\begin{tabular}{lllll}
\hline \multirow{2}{*}{ Type of job satisfaction } & Trakya University Hospital & State hospital & Private hospital & pean \pm SD \\
\cline { 2 - 5 } & Mean \pm SD & Mean \pm SD & $3.77 \pm 0.49$ & 0.045 \\
\hline Intrinsic satisfaction & $3.43 \pm 0.63$ & $3.38 \pm 0.64$ & $3.26 \pm 0.54$ & 0.010 \\
Extrinsic satisfaction & $2.93 \pm 0.63$ & $2.79 \pm 0.68$ & $3.57 \pm 0.40$ & 0.014 \\
General satisfaction & $3.23 \pm 0.56$ & $3.15 \pm 0.60$ & \\
\hline
\end{tabular}

*One way analysis of variance (ANOVA).

When job satisfaction and subtitles were evaluated by institutions, it was observed that the mean extrinsic and general satisfaction scores were above 3 (favorable) in all three institutions. However, the extrinsic satisfaction scores in the healthcare staffs in TUH and in the state hospital were observed to be below 3 and lower compared to the healthcare staffs in the private hospital.

When general job satisfaction and subtitles were examined by occupations, the results in Table 3 were obtained. Intrinsic job satisfaction is higher in specialist physicians and academicians. General job satisfaction in specialist physicians is higher compared to research assistants and general practitioners; general job satisfaction in academicians is higher compared to research assistants, general practitioners and nurses.

Table 3. Distribution of the Minnesota Satisfaction scale scores of the healthcare staffs included in the study by occupational groups and titles.

\begin{tabular}{llll}
\hline Title & Intrinsic satisfaction Mean \pm SD & Extrinsic satisfaction Mean \pm SD & General satisfaction Mean \pm SD \\
\hline Academicians & $3.93 \pm 0.42$ & $3.00 \pm 0.58$ & $3.56 \pm 0.42$ \\
Research assistants & $3.23 \pm 0.65$ & $2.80 \pm 0.63$ & $3.06 \pm 0.58$ \\
Specialist physicians & $3.73 \pm 0.50$ & $3.91 \pm 0.66$ & $3.40 \pm 0.46$ \\
General practitioners & $3.13 \pm 0.24$ & $3.69 \pm 0.55$ & $2.95 \pm 0.33$ \\
Nurses & $3.33 \pm 0.62$ & $2.92 \pm 0.67$ & $3.16 \pm 0.59$ \\
p & 0.001 & 0.338 & 0.001 \\
\hline
\end{tabular}

According to these findings, the intrinsic satisfaction scores of the physicians and nurses were above the neutral score. The extrinsic satisfaction scores of the academicians and nurses were below the neutral score and the general satisfaction scores of the physicians were below the neutral score.

While the majority of the healthcare staffs (76.9\%) included in the study was working for a mean time of 9 hours daily, they $23.1 \%$ reported that they were working more than 9 hours a day.

General job satisfaction scores were found to be higher in the heatlhcare personnels who worked for a mean time of 9 hours and less a day and in the healthcare staffs who had weekly regular working hours of 45 hours in the institution where they worked.

When the salaries of the healthcare staffs which are in the first order among the reasons of job dissatisfaction were examined by institution and occupational group, it was found that the difference between all institutions and occupational groups was significant $(\mathrm{p}<0.05)$.

One of the important findings obtained in this study was the fact that $263(68.3 \%)$ of the healthcare staffs thought that performance evaluation was unfair in the institution where they worked.

It was observed that the factors which generally affected job satisfaction in all institutions included occupation, institution, division, working time, salary, performance evaluation, type of working, administrative position.

\section{Discussion}

The results of the study showed that the intrinsic satisfaction scores were above the neutral score in physicians and nurses, the extrinsic satisfaction scores were below the neutral score in research assistant and nurses and the general satisfaction scores were below the neutral score.

When evaluation was made by occupational groups and titles, the general ordering for job satisfaction was as follows: academicians, specialist physician, nurse, research assistants and general practitioner. In the study of Kvist et al. [5], according to occupational comparison, the job satisfaction rankings were physicians, research assistants and nurses. Some studies have found that nurses have more job satisfaction than physicians $[6,7,8]$. Some studies showed that, there is no statistical difference between physicians and nurses in terms of job satisfaction. [9, 10].

In this study, no correlation was found between gender and job satisfaction. When similar studies were examined, evidence showing that there was no statistically significant correlation between job satisfaction and gender was found [9, $11,12]$. Some studies showed that women had higher job satisfaction scores compared to men [13].

In this study, the individuals who aged 19 years and below had the highest job satisfaction scores, while the ones between 50 and 59 years had the lowest job satisfaction scores. Job satisfaction tended to increase rapidly in the individuals who aged 60 years and older. In addition to the research supporting this data $[13,14]$, different correlations have also been found between age and satisfaction in different studies $[15,16]$. Some studies showed that no significant difference was found between age and satisfaction $[9,11,17]$.

Although the job satisfaction scores were found to be lower in the subjects who were single compared to the ones who were married in this study but no correlation was found 
between marital status and job satisfaction in the studies of Cagan et al. [9], Aldrees et al. [11].

According to the studies of Lomber et al. [2] and Jeong et al. [16], job satisfaction increases as the education level increases. While the highest level of job satisfaction has been observed in postgraduates, the lowest job satisfaction has been found in high-school graduates. Similarly, job satisfaction increased as the education level increased in this study. The high level of job satisfaction in the individuals with a bachelor's degree and in postgraduates may be explained with the factors including status, relatively better personal rights, high levels of expectation and promotion/advancement. In the study of Haijuan et al. [14] job satisfaction which is low in high-school graduates increases in individuals with an associate's degree and decreases again as the education level increases. This is similar to the results of this study. In some studies no correlation were found between education level and job satisfaction. [6, 17, 18]

Another variable investigated in terms of job satisfaction was status. According to Lu et al. [6] healthcare staffs with a lower professional status were more satisfied with their job than those with a higher professional status. But in the study of Mehrdad et al. [17] no significant correlation was found between status and job satisfaction. In this study, job satisfaction levels were found to be similar in the healthcare staffs who had different statuses.

Working in the state hospital or private hospital shows significant differences in terms such as workload, income, working environment. According to these results, the job satisfaction level in the healthcare staffs who worked in the private hospital was higher compared to the ones who worked in the state institutions. There are studies in the literature that support findings of the study. [19, 20]. This may be explained with the fact that the working conditions and salaries are better for physicians who work in private hospitals compared to the ones who work in the other institutions.

Long-term working in the same institution and seniority in profession may lead to positive results in terms of many aspects including social environment, sense of belonging, knowledge and ownage of the institution, self-confidence and experience. These positive feelings may also affect job satisfaction positively. Therefore, working period in the institution and job experience are the variables which are evaluated frequently in studies related with job satisfaction. For example, it was found that the general satisfaction levels were higher in the individuals who had been working in the same institution for 16 years and more compared to the ones who had been working in the same institution for a shorter period in the study of Jeong et al. [16]. The results of this study are similar in this aspect.

The department of working healthcare staffs is one of the most important parameters in job satisfaction. In Nylenna et al. [21] study, job satisfaction was high in public health, psychiatry and family medicine branches, low in internal medicine and anesthesia branch. In Purpora et al. [12] study, there is no statistically significant result between the department of working and job satisfaction. In this study, all job satisfaction scores were found to be significantly higher in the healthcare staffs who worked in basic sciences compared to the other divisions. The probable reasons for this may be lack of patient follow-up, lack of one to one relations with patients and relatives, a low risk of negativities including exposure to violence, more regular working hours and lack of being on duty for healthcare staffs who work in basic sciences.

Another interesting finding of this study was the effect of status of feeling sufficient in the job on job satisfaction. When these results were evaluated in terms of this parameter which was never studied before, it was found that job satisfaction increased, if the healthcare staffs working in the hospitals in Edirne central district found themselves sufficent in the job.

In many studies related with the issue, it has been found that healthcare staffs who are not satisfied with their jobs and/or the institution where they work have a low level of job satisfaction. In the studies of Pillay [20] and Yami et al. [22], they were found that the healthcare staffs who thought to leave their institutions had a lower level of job satisfaction. Similarly, job satisfaction was found to be lower in the healthcare staffs who thought to change their jobs in the study conducted by Ezzat et al. [23]. This study is similar to the literature in terms of these two variables in question (thinking of changing job or institution).

In the study of Aiken et al. [24] conducted with nurses, it was found that one of every 3 nurses working in Sweden and Scotland and one or more than one of every 5 nurses working in America planned to quit their jobs. Job satisfaction was lower in the healthcare staffs who thought to quit their jobs compared to the ones who were satisfied with their jobs similar to this study.

One of the main factors which may affect job satisfaction is salary. Lack of a salary which would meet the employee's needs leads to job dissatisfaction. The correctness of this thesis has been proven with studies. [9, 22, 25-27] Job satisfaction was found to be high in the healthcare staffs who were satisfied with the salary they received in this study in accordance with the literature findings.

Being included in the mechanism of decision making and having an administrative position may sometimes affect job satisfaction. For example, job satisfaction was found to be higher in the healthcare staffs who had an administrative position in he study of Konstantinos et al. [28] and in the study of Ranz et al. [29]. The results of the study are similar in this aspect. It was found that the healthcare staffs who has an administrative position had higher general satisfaction scores in this study.

Some of the factors which seperate healthcare staffs from the other professions include long working hours, irregular working style and night shifts. Studies conducted in this area have shown that job satisfaction is affected negatively in the healthcare staffs who work more than 8 hours a day, who have weekly working hours which are unclear or irregular and who have more than 3 
night shifts a week $[1,6]$. The results of the study are similar to the studies mentioned above.

The status of exposure to psychological violence in the work place, status of experiencing trauma and feeling safe in the institution where one worked were the other variables which were questioned in terms of job satisfaction in this study. In literature search, job satisfaction was found to be related with the factors mentioned in almost all studies in which these variables were studied $[12,23]$. In the study of Konstantinos et al. [28], it was found that the quality of clinic managers and exposure to psychological stress decreased job satisfaction. In the study, job satisfaction scores were also found to be low in the healthcare staffs who experienced problems, who experienced psychological trauma and who were exposed to verbal or physical violence by patients and relatives and who did not feel secure in the workplace.

Another important issue which emerged in the area of healthcare with health transformation in the country is performance related pay. This system which rendered sense of justice questionable among healthcare staffs may sometimes affect motivation and job satisfaction in a negative way. Job satisfaction is affected negatively in healthcare staffs who think that payment is not fair. For example, job satisfaction was found to be lower in the nurses who thought that performance related pay system was not applied fairly in the study of Karakuş [30]. According to this system, physicians receive additional payments for the patients they have examined, the patients they have operated on, and the patients for whom they have done intervetional treatments. Physicians have a particular points for each procedure, surgery and examination they do. These points are collected at the end of each month. An additional payment is made to each physician from his/ her income as much as his/ her point. However, some physicians think that their unit points are not enough. Physicians believe that they deserve more money for the hard work they do. They believe that performance-based payment is unfair. In the study, the healthcare staffs who thought that performance related pay system was not applied fairly also had a lower job satisfaction level. Since this system is not similar in the world, no comparison were made with other countries.

\section{Conclusion}

The general job satisfaction was better in individuals who were experts in their areas, who worked in private hospital, who loved their profession, whose working hours were regular, who felt themselves safe in their institutions and who worked free from violence. The worst level of job satisfaction was found in general practitioners.

When all study results were examined, it was found that the healthcare staffs who were working in hospitals in Edirne central district and especially who were working in the state sector experienced important problems in terms of job satisfaction. Job satisfaction was negatively affected by many variables ranging from working conditions to personal rights.
Hence, job satisfaction levels of nurses and physicians working in all units at certain intervals should be evaluated. The way of working and the hours should be arranged in such a way that it does not significantly affect the work and social life of health staffs. The number of health staff should be increased to solve this problem. The performance-based payment system must be removed or reclaimed.

\section{Conflicts of Interest}

All the authors do not have any possible conflicts of interest.

\section{Acknowledgements}

We would like to thank all the healthcare personnel who helped to carry out this study, the management of the hospitals where this study was done.

\section{References}

[1] Chien WT, Yick SY. An investigation of nurses' job satisfaction in a private hospital and its correlates. Open Nurs J. 2016 May 27; 10: 99-112. doi:

10.2174/1874434601610010099. Ecollection 2016. 2016, 10, 99-112.

[2] Lorber M, Skela Savič B. Job satisfaction of nurses and identifying factors of job satisfaction in Slovenian hospitals. Croat Med J. 2012 Jun; 53 (3):263-70.

[3] Pietersen C. Job satisfaction of hospital nursing staff. SA Journal of Human Resource Management, 2005, 3 (2), 19-25.

[4] Baycan AF. Analysis of the several aspects of job satisfaction between different occupational groups. Masters Thesis (unpublished), Bogazici University Institute of Social Sciences, 1985.

[5] Kvist T, Mäntynen R, Vehviläinen-Julkunen K. Does Finnish hospital staff job satisfaction vary across occupational groups? BMC Health Services Research 2013; 13:376 DOI: 10.1186/1472-6963-13-376.

[6] Lu Y, Hu XM, Huang XL, Zhuang XD, Guo P, Feng LF, Hu W, Chen L, Hao YT. Job satisfaction and associated factors among healthcare staff: A cross-sectional study in Guangdong Province, China. BMJ Open. 2016 Jul 19; 6 (7): e 011388. doi: 10.1136/bmjopen-2016-011388.

[7] Jaiswal P, Gadpayle AK, Singhal AK, Sachdeva S, Modi RK, Padaria R, Ravi V. Job satisfaction among hospital staff working in a government teaching hospital of India. Medical Journal of Dr. D. Y Patil University. 2015; 8 (2):131-137.

[8] Mundongo TH, Ditend YG, VanCaillie D. Malonga KF. The Assessment of Job Satisfaction For The healthcare providers in university clinics of Lubumbashi, Democratic Republic of Congo. Pan Afr Med J. 2014; 19: 265. Published online 2014 Nov 11. doi: 10.11604/pamj.2014.19.265.3138.

[9] Cagan O, Gunay O. The job satisfaction and burnout levels of primary care health workers in the province of Malatya in Turkey. Pak J Med Sci. 2015; 31 (3):543-7. doi: 10.12669/pjms.313.6795. 
[10] Martins OF, Tukur D, Danburam A, Salwau FK., Job satisfaction among doctors and nurses: A case study of Federal Medical Centre Yola, Nigeri. Int J Community Med Public Health. 2016 Jun; 3 (6):1640-1647.

[11] Aldrees T, Al-Eissa S, Badri M, Aljuhayman A, Zamakhshary M. Physician job satisfaction in Saudi Arabia: insights from a tertiary hospital survey. Ann Saudi Med. 2015 May-Jun; 35 (3):210-3. doi: 10.5144/0256-4947.2015.210.

[12] Purpora C, Blegen MA, Job satisfaction and horizontal violence in hospital staff registered nurses: the mediating role of peer relationships. J Clin Nurs. 2015 Aug; 24 (15-16):228694. doi: 10.1111/jocn.12818. Epub 2015 May 4.

[13] Carrillo-García C, Solano-Ruíz Mdel C, Martínez-Roche ME, Gómez-García CI. Job satisfaction among health care workers: the role of gender and age. Rev Lat Am Enfermagem. 2013 Nov-Dec; 21 (6):1314-20. doi: 10.1590/0104-1169.3224.2369.

[14] Haijuan W, YongPin N, BiBo X. Main factors influencing nurse job satisfaction- A cross-country study. (Master's Thesis), Kristianstad Univ. College; 2006.

[15] Tarcan M, Hikmet N, Schooley B, Top M, Tarcan GY. An analysis of the relationship between burnout, sociodemographic and workplace factors and job satisfaction among emergency department health professionals. Appl Nurs Res. 2017 Apr; 34: 40-47. doi: 10.1016/j.apnr.2017.02.011. Epub 2017 Feb 3.

[16] Jeong EY. Empowerment and job satisfaction among clinical nurses in south korea: systematic review. J Korean Acad Nurs Adm. 2013; 19(5):599-612.

[17] Mehrdad R, Izadi N, Pouryaghoub G. Nurse job satisfaction: Is a revised conceptual framework needed? International Journal of Hospital Research 2013, 2(2):55-60.

[18] Ge C, Fu J, Chang Y, Wang L. Factors associated with job satisfaction among Chinese community health workers: a cross-sectional study. BMC Public Health. 2011 Nov 24; 11: 884. doi: 10.1186/1471-2458-11-884.

[19] Hamid S, Malik AU, Kamran I, Ramzan M. Job satisfaction among nurses working in the private and public sectors: a qualitative study in tertiary care hospitals in Pakistan. J Multidiscip Healthc. 2014; 7: 25-35.
[20] Pillay R. Work satisfaction of professional nurses in South Africa: a comparative analysis of the public and private sectors. Hum Resour Health. 2009 Feb 20; 7: 15. doi: 10.1186/1478-4491-7-15.7:15.

[21] Nylenna M, Gulbrandsen P, Førde R, Aasland OG. Unhappy doctors? A longitudinal study of life and job satisfaction among Norwegian doctors 1994-2002. BMC Health Serv Res. 2005 Jun 8; 5: 44.

[22] Yami A, Hamza L, Hassen A, Jira C, Sudhakar M. Job Satisfaction And Its Determinants Among Health Workers In Jimma University Specialized Hospital, Southwest Ethiopia. Ethiop J Health Sci. 2011 Aug; 21 (Suppl 1):19-27.

[23] Ezzat HA, Lashin O. Violence on Hospital Nurses and Job Satisfaction. New Egyptian journal of medicine. 2005 Sep.; 32(6).

[24] Aiken LH, Clarke SP Sloane DM, sochalski J. Cause for concern: nurses' reports of hospital care in five countries. LDI Issue Brief. 2001 May; 6 (8):1-4.

[25] Negussie N. Job satisfaction of nurses in Jimma University Specialized Teaching Hospital, Ethiopia. J Egypt Public Health Assoc. 2016 Mar; 91 (1):15-9. doi: 10.1097/01. EPX.0000480719.14589.89.

[26] Hu J, Liu H. Job Satisfaction among Nurses in China. Home Health Care Manag \& Pract 2004; 17: 9-13.

[27] Abushaikha L, Saca-Hazboun H. Job satisfaction and burnout among Palestinian nurses. East Mediterr Health J. 2009 JanFeb; 15 (1):190-7.

[28] Konstantinos N, Christina O. Factors influencing stress and job satisfaction of nurses working in psychiatric units: A research review. HSJ 2008; 2(4), 183-95.

[29] Ranz J, Stueve A. McQuistion HL The role of the psychiatrist: Job satisfaction of medical directors and staff psychiatrists. Community Mental Health J 2001; 37(6), 525-39.

[30] Karakuş H. Hemşirelerin iş tatmin düzeyleri: Sivas ili örneği. Dicle Üniv Sosyal Bilimler Enstitüsü Derg 2011; 3 (6):46-57. Turkish. 